\title{
Nitrogen Distribution Model: A Farmer and Farm-Centred Model to Monitor N Movement in the Soil
}

\author{
J. Mthandi ${ }^{*}$, F. C. Kahimba1, A. K. P. R. Tarimo¹, B. A. Salim¹, M. W. Lowole ${ }^{2}$ \\ ${ }^{1}$ Department of Agri. Eng. and Land Planning, Sokoine University of Agriculture, Morogoro, Tanzania \\ ${ }^{2}$ Department of Crop Science, Bunda College of Agriculture, Lilongwe, Malawi \\ Email: *johnmthandi@yahoo.com
}

Received 23 September 2014; revised 15 October 2014; accepted 7 November 2014

Copyright (C) 2014 by authors and Scientific Research Publishing Inc.

This work is licensed under the Creative Commons Attribution International License (CC BY). http://creativecommons.org/licenses/by/4.0/

c) (i) Open Access

\begin{abstract}
There are several models that monitor movement of nitrogen in the soil. Most of these models have not been widely used in southern Africa because of sophisticated equipment required to collect data and the data needed to run the model are intensive. Nitrogen Distribution Model (NDM) has been developed to ensure that it responds to increasing need of managing nitrogen in agricultural systems characterized by smallholder farmers who do not have adequate resources to collect intensive data for modeling. NDM has parameters that are explicit and mostly intuitive and maintains good balance of simplicity and robustness. With the nature of smallholder farming in Malawi where over $85 \%$ of population are rural-based smallholder farmers, the model has also be designed so that it can acts as database to keep track of farmers and farms so that were given farm-specific nitrogen and water management advice.
\end{abstract}

\section{Keywords}

Nitrogen Distribution Model, Modeling, Water, Nitrogen

\section{Introduction}

Nitrogen $(\mathrm{N})$ is the most important determinant of plant growth and crop yield. Plants lacking $\mathrm{N}$ show stunted growth and yellowish leaves. Plant growth and crop yield usually increase when $\mathrm{N}$ is added [1]. However, too much $\mathrm{N}$ can also cause problems which may extend to plants, humans, animals, and the environment. For example, in plants, too much $\mathrm{N}$ will lead to weak stems in grain crops (lodging), reduce quality in fruit such as

${ }^{*}$ Corresponding author.

How to cite this paper: Mthandi, J., Kahimba, F.C., Tarimo, A.K.P.R., Salim, B.A. and Lowole, M.W. (2014) Nitrogen Distribution Model: A Farmer and Farm-Centred Model to Monitor N Movement in the Soil. Journal of Water Resource and Protection, 6, 1546-1552. http://dx.doi.org/10.4236/jwarp.2014.616141 
peaches and apples, lower sugar content in sugar beets, and may lead to an accumulation of nitrate in the edible foliage of plants such as spinach and forage crops [2]. $\mathrm{N}$ can contaminate groundwater to a point at which it may become a health hazard $(10 \mathrm{ppm})$. Matching $\mathrm{N}$ availability in soil solution and crop uptake needs is critical to improving maize production. [3] reported that best nitrogen and water management practices can reduce the probability of nitrate leaching into groundwater and maintain profitable yields. The big question in the management of nitrogen has been how much nitrogen is enough in crop production for give desirable crop yields with low cost while avoiding excess $\mathrm{N}$-induced problems. Owing to the complexity of soil and crop systems, it is difficult to account for the observed $\mathrm{N}$ responses, and to ascertain that specified output is the result of a specified $\mathrm{N}$ input [4]. The behavior of $\mathrm{N}$ in the soil system is complex, yet an understanding of basic processes is essential for a more efficient $\mathrm{N}$ management program [5]. The basic processes of Nitrogen in soil are leaching, denitrification, volatilization, crop removal, and soil erosion and runoff. Leaching is the loss of soluble $\mathrm{NO}_{3}^{-}$as it moves with soil water below the root zone. Nitrate can be leached from any soil applied water exceeds the water holding capacity of the soil leaving additional water to freely move down through the soil profile with soluble nitrogen. Understanding of movement of water with solute in soil can help to reduce nitrogen losses through leaching and maximize economic returns of smallholder farmers. The movement of $\mathrm{N}$ in the soil is influenced by leaching and crop removal. Leaching which is due to movement of nitrogen is governed by advection and dispersion equations while crop removal is governed by rate of plant uptake. The majority of nitrate ions $\left(\mathrm{NO}_{3}^{-}\right)$do not bind to the soil solids because they carry negative charges and are greatly influenced by advection (defined as the flux of solute due to the movement of water containing the solute). The movement of any solute including nitrogen in the soil where maize is growing is given as follows [6]:

$$
\frac{\partial \theta c}{\partial t}=\frac{\partial}{\partial x_{i}}\left(\theta D_{i j} \frac{\partial c}{\partial x_{j}}\right)-\frac{\partial q_{i} c}{\partial x_{i}}-N_{u}\left(c, x_{i}, t\right)
$$

This mathematical expression has all three factors that influence the movement of nitrogen in the soil and these are advection, dispersion and plant nitrogen uptake.

This paper presents the work and steps used to develop NDM. NDM has been developed to ensure that it responds to increasing need of managing nitrogen in agricultural systems characterized by smallholder farmers who do not have adequate resources to collect intensive data for modeling. NDM has parameters that are explicit and mostly intuitive and maintains good balance of simplicity and robustness.

\section{Methodology}

\subsection{Advection-Dispersion Equation}

The modes of nitrogen transport in soil are predominantly governed by advection and dispersion [6]-[8]. The mathematical expression of Advection-Dispersion Equation is given as follows:

$$
\frac{\partial \theta c}{\partial t}=\frac{\partial}{\partial x_{i}}\left(\theta D_{i j} \frac{\partial c}{\partial x_{j}}\right)-\frac{\partial q_{i} c}{\partial x_{i}}
$$

where, $t$ is time, $c$ is the $\mathrm{N}$ concentration in the liquid phase, $x_{i}$ and $x_{j}(i, j-1,2)$ are spatial coordinates, $D_{i j}$ are components of dispersion coefficient tensor, $q_{i}$ is the $i$ th component of the volumetric flux density. The volumetric flux density $(q)$ to be employed in the above equation determines the nature of transport of dissolved $\mathrm{N}$ with flowing water. Thus, use of the flow equation is required to calculate the volumetric flux density.

\subsubsection{Advection Equation}

Advection is defined as the flux of solute due to flow of water containing the solute. It is a product of water flux and the solute concentration $(c)$ and can simply be expressed as [9]:

$$
\left(\frac{\partial c}{\partial t}\right)_{m}=q_{w} c
$$

1) Determination of $\mathrm{N}$ concentration of solute in the soil

The following equation was used to calculate concentration of nitrogen in the soil. 


$$
\mathrm{C}=\operatorname{ar} /(\mathrm{bd} * 1000 * \text { dlayer } * 10)
$$

where:

- C is concentration of solute $\left(\mathrm{kg} / \mathrm{L}^{3}\right.$ of soil);

- $\quad$ ar is $\mathrm{N}$ application per hectare $(\mathrm{kg} / \mathrm{ha})$;

- bd is bulk density $\left(\mathrm{g} / \mathrm{m}^{3}\right)$;

- dlayer is depth of layer (mm).

Solute is substance dissolved in a liquid. Concentration is measured in [mass/length3] (mg/L). Concentration is function of time, directions, $c(x, y, z, t)$.

2) Determination of water flux $\left(q_{w}\right)$

Triscan Sensor was used to collect soil water content in $(d)$ depth of water in each layer ( $\mathrm{L}$ of water/L of soil). This water depth was multiplied by row spacing $(r)$ and planting spacing $(s)$ to have $(q)$ volume of water available within each layer of maize root zone as presented in below equation:

$$
q=d * r * s(\text { dimensions in } \mathrm{mm})
$$

The water flux $q_{w}$ was determined by considering volume of water $(q)$ crossing the cross-section area of maize rootzone $\left(\mathrm{mm}^{3}\right)$, lateral conductivity $\left(K_{h}\right.$ in $\mathrm{mm} /$ day), and ground surface slope $(\mathrm{m} / \mathrm{m})$ as presented in equation below:

$$
q_{w}=K_{h} * q * s /\left(1+s^{2}\right)^{0.5}
$$

where:

$K_{h}=$ horizontal conductivity (mm/day);

$q=$ soil volumetric water content;

$s=$ surface slope $(\mathrm{m} / \mathrm{m})$.

\subsubsection{Dispersion Equation}

Dispersion is the spreading out of solute due to variations in water velocity within individual pores, across pores with differing sizes and shapes, and across interconnected pore pathways with different geometries. It allows solute to come to an equilibrium concentration within the soil solution and between regions where the soil solution is mobile or immobile [10]:

$$
\left(\frac{\partial c}{\partial t}\right)_{h}=-D_{e}\left(\frac{\partial c}{\partial x}\right)
$$

where $(\partial c / \partial t)_{h}$ is the solute flux due to dispersion;

$D_{e}$ is the dispersion coefficient, estimated as follows [11] [12]:

$$
D_{e}=D \theta \tau
$$

where:

- $D$ is the diffusion coefficient in water filling the pores (for $\mathrm{N}$ in water is $1.88 \times 10^{-5} \mathrm{~m}^{2} \cdot \mathrm{s}^{-1}$ );

- $\tau$ is the tortuosity of soil (dimensionless), values are between 0.21 to 0.35 for unsaturated sandy loam soils, and between 0.59 to 0.84 for saturated sandy loam soil by [13];

- $\theta$ is soil volumetric moisture content.

\subsection{Plant Nitrogen Uptake}

Another influence that will determine nitrogen movement in the soil is plant uptake. The uptake of water and nutrients by plant roots will create a gradient in regions surrounding the roots. With the general principle of hydraulic gradient influencing water movement, then water and nitrogen will move towards plant roots where there is a negative gradient. Plant nitrogen uptake, $N_{u}$, is the function of time and coordinates. It is related to water uptake in that the nutrient gets taken up by the plants with the water. The $N_{u}$ is governed by the following equation:

$$
N_{u}\left(c, x_{i}, t\right)=c(x, z, t) S
$$




$$
S(h)=\alpha(h) S_{\max }
$$

where $\alpha(h)$ is a prescribed dimensionless function of the soil pressure head ranging between 0 and 1 . Soil pressure is a function of soil moisture content in the soil. At saturation point, soil pressure is 0 and soil pressure head is 1 . At wilting point soil pressure is at maximum and is 1 while soil pressure head is 0; i.e. At SAT, $\alpha(h)=1$, at LL15, $\alpha(h)=0$ (Boundary).

$S_{\max }$ is the potential water uptake rate which equal to crop evapotransipiration $\left(S_{\max }=\right.$ ETc).

\section{Development of NDM}

The left graph of Figure 1 shows that concentration of solute in soil decreases with time. For example, before application of nitrogen fertilizer, the concentration of nitrogen was low but when nitrogen fertilizer was applied, the concentration of nitrogen increased. Due to leaching and uptake by maize, nitrogen concentration decreased. The right graph of Figure 1 shows that at point where nitrogen fertilizer has been applied, the concentration of nitrogen is high compared to the surroundings.

The following assumptions have been drawn from Figure 1 and have been used in development of the model.

1) At the time of fertilizer application, the soil where fertilizer is applied has highest concentration of nitrogen than the surroundings;

2) Movement of nitrogen is from the point of application to the surrounding;

3) Concentration is mass of nitrogen/volume of soil (to be calculated by bulk density);

4) All $\mathrm{NH}_{4}-\mathrm{N}$ in fertilizer is converted to $\mathrm{NO}_{3}-\mathrm{N}$ immediately upon fertilizer application, and is completely dissolved in applied water;

5) There is no capillary rise, and water table lies far below the surface.

\subsection{Input and Output Variables of the Model}

NDM has been developed by including all three factors that influence solute transport in the soil and these are advection, dispersion and plant uptake. It would have been difficult to use the model if the input parameters were soil moisture content, rate of nitrogen uptake by maize plant, concentration of nitrogen in the soil because cost associated with equipment need to capture such type of data. In order to simplify the model, the input parameters have been simplified to volume of water applied in $\mathrm{m}^{3}$ and the model is then generating the depth of water in $\mathrm{mm}$. The depth of applied water in the soil is linked to calculation of soil moisture content. The input parameter of the model is quantity of fertilizer applied in $\mathrm{kg} / \mathrm{ha}$ and the model is generating quantity of nitrogen applied presented in $\mathrm{N} \mathrm{kg} / \mathrm{ha}$. This input parameter is linked to the nitrogen concentration in the soil, which is an integral component of both advection and dispersion equations present in Equation (1). The other input parameter that has been used in the model is maize growth stage. The maize growth stage such as emergence, development, mid- and late-stages is generating crop coefficient $\left(K_{c}\right)$ which is being used to calculate actual crop evapotranspiration $\left(\mathrm{ET}_{c}\right)$. The $\mathrm{ET}_{c}$ has been assumed as potential water uptake rate $\left(S_{\max }\right)$ in the uptake component of the equation.

The model has included two other input parameters of farmer and farm. The input parameters under farmer consists of name of a farmer, district, Traditional Authority (TA), village and his/her mobile number. The farm
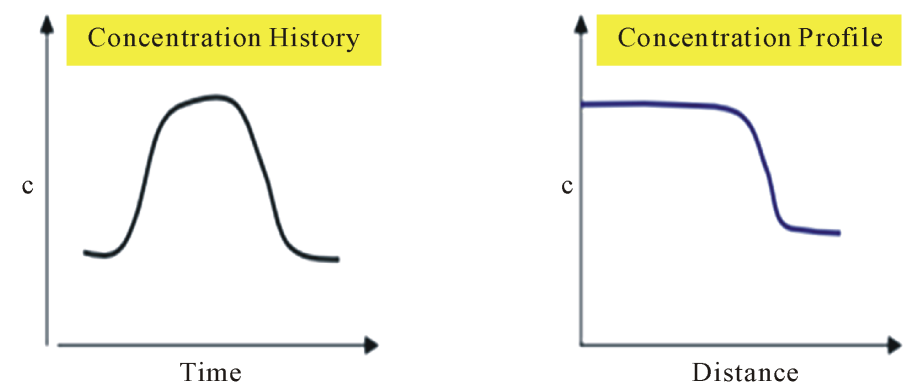

Figure 1. It shows behaviors of concentration with respect to time and distance. 
input parameters consists of land under cultivation, general slope of the farm, general soil type, irrigation method, and district where the farm is ( here the model has assumed that some farmers might have two or more farms in different districts). These input parameters have been included to ensure that the model is farmer-centered that will enable them to have specific recommendations as per their specific agricultural production requirements. Figure 2 shows a schematic diagram of NDM with input and output information.

\subsection{The Input Data Files of the Model}

The NDM has five input data files namely Farmer Date file, Farm Data file, Water Data file, Fertilizer Data file, and Crop Data file. Within each data file, there are more than three input parameters that need to be entered in the model. These input parameters have been designed in such way that they are not difficult for users to collect and input them in the model. If the data input requires sophisticated equipment to collect them in the field, it may limit the wider application of the model [14].

The NDM is written in programming language of $\mathrm{C}++$. The model used this programming language because NDM was developed so that it can be incorporated in the Soil Water Module of APSIM model as subroutine. The programming language of APSIM is $\mathrm{C}++$; hence to ensure compatibility, the NDM had to be developed in the same programming language. Figure 3 shows the flow chart of the model.

\subsection{The Nitrogen Distribution Model Interface}

Figure 4 presents the interface of the NDM. The interface has four main input data sets namely Farmers and Farms under general information category, and Water and Fertilizer under inputs category. The last category of processes has Simulation and Set up.

When clicked on Farmer file, the four operations will appear and these are New farmer, Update Farmer Details, Delete Farmer or Add Farm. The user will select the operation that he/she want to operate. Another advantage of this model is that it also acts as database to keep information of farmers and their farms; hence it is easy to track and give advice to farmers.
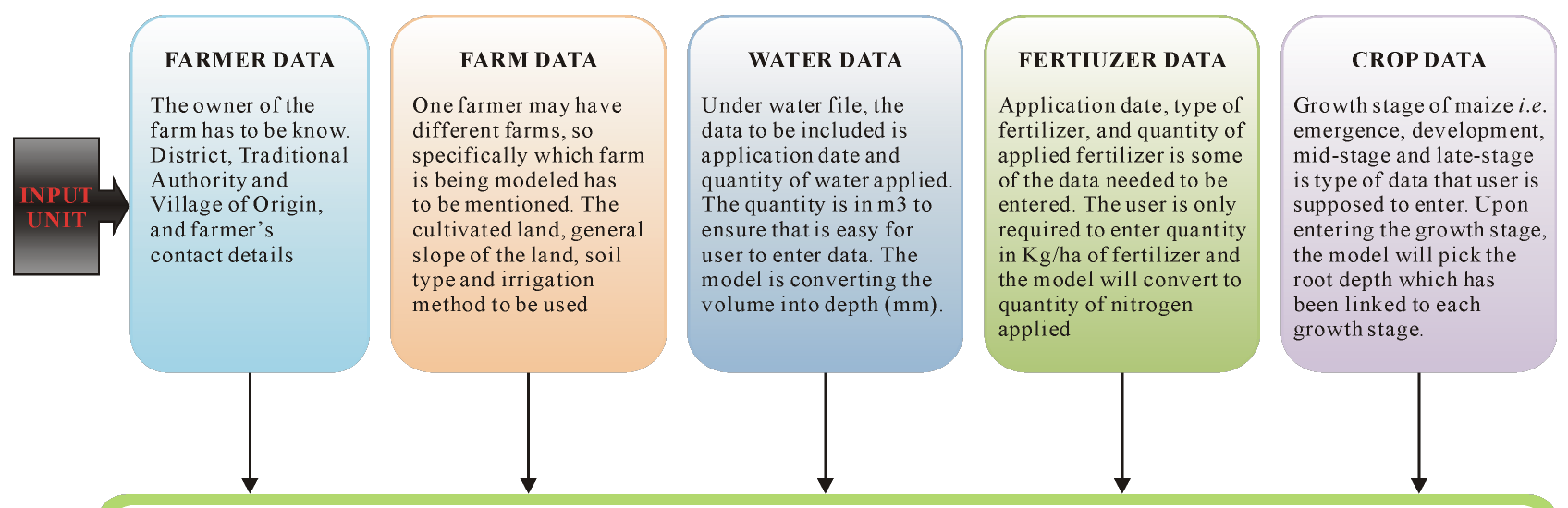

NITROGEN DISTRIBUTION MODEL PROGRAMME

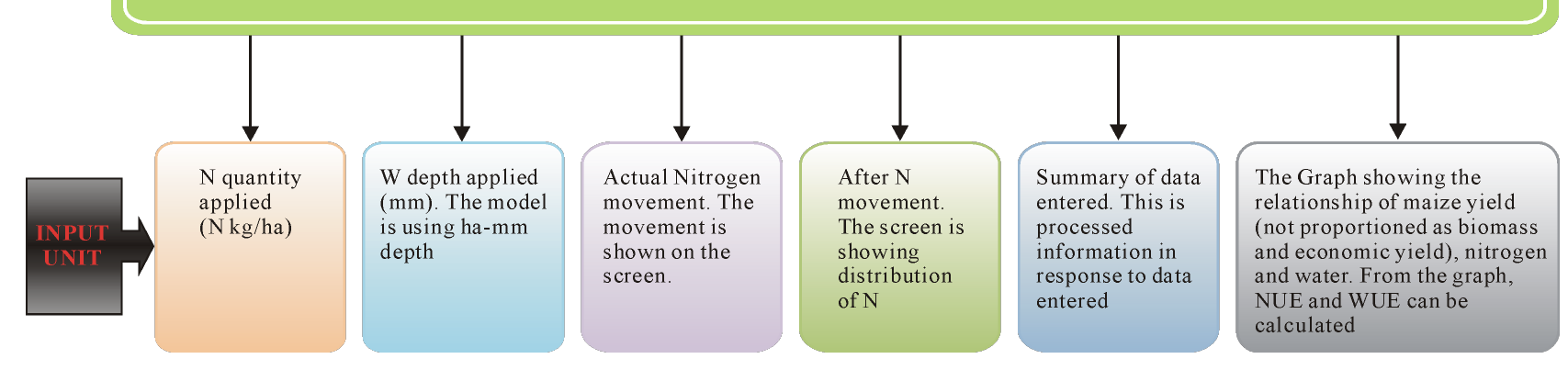

Figure 2. Schematic diagram of NDM with input and output information. 


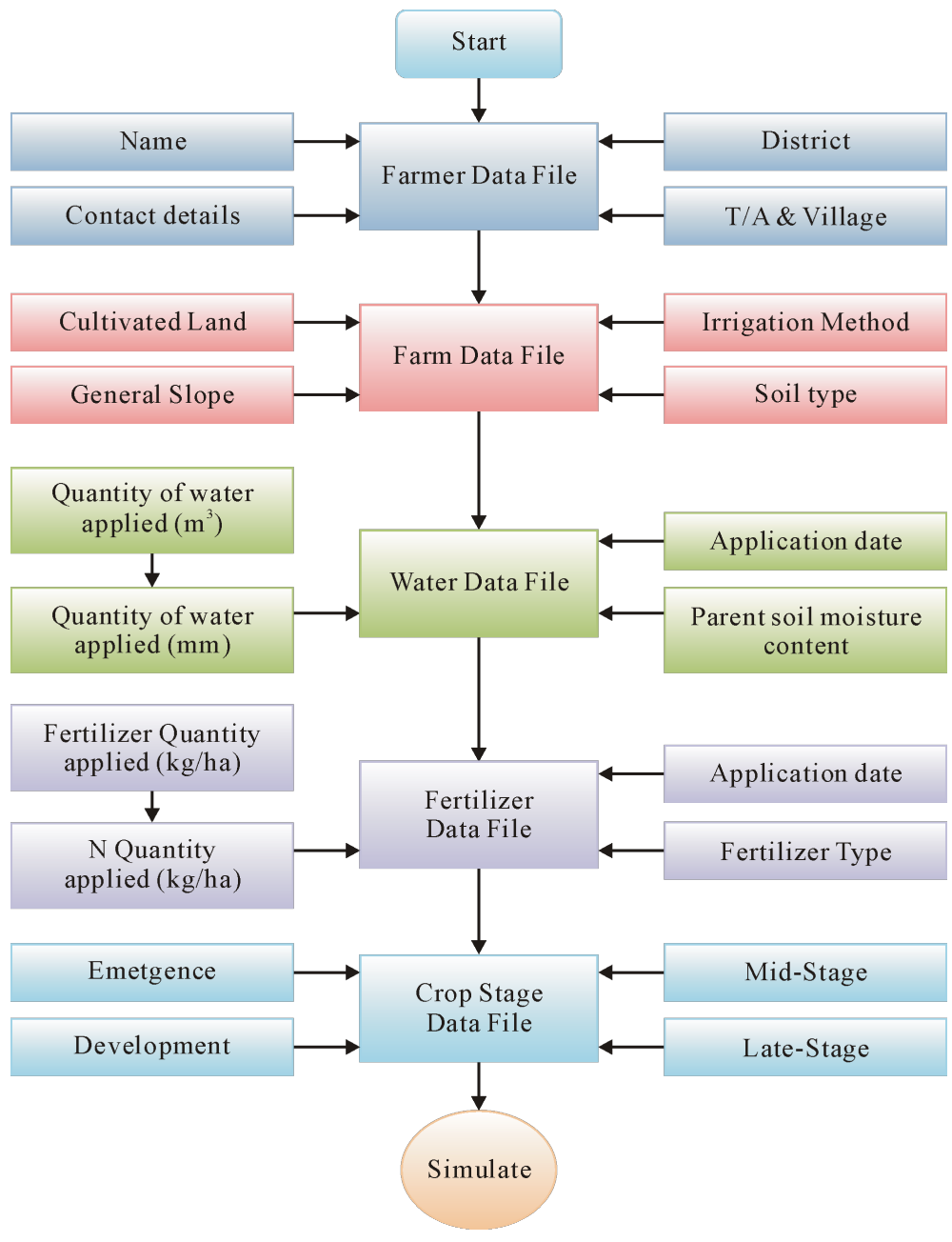

Figure 3. Flow chart of the NDM.

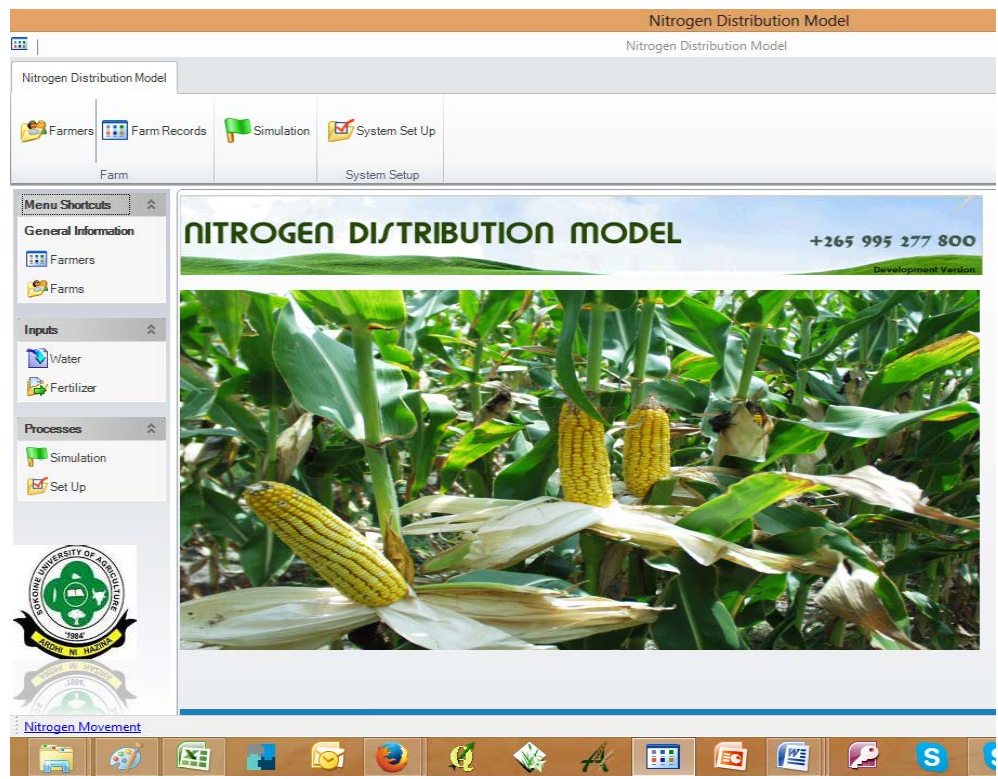

Figure 4. Model user interface. 
After data is entered under farmer file, the next step is to enter details of the farm. The model has assumed that one farmer might have different farms with different characteristics. In fact, the agricultural production system of most of the smallholder farmers is that they have several patches of land which they for crop production. This model has taken this agricultural production system into consideration. The model would provide information to farm specific.

\section{Conclusion}

The conceptual framework, design, structure and key algorithms of the NDM have been described to highlight the distinctive features and peculiarities of the model. The model requires low number of parameters and input data to simulate movement and distribution of nitrogen in the soil under irrigation. Unlike other previous similar models, the strength of this model is that input parameters are very minimum and easy to capture and enter in the interface. To capture the input parameters of water and nitrogen does not sophiscated equipment and hence smallholder farmers. The parameters of the model are explicit and maintain good balance of accuracy, simplicity and to some extent robustness. The model is aimed at ensuring that informed decisions are made on proper management of water and nitrogen resources on a farm. Another important application of the model is that it can be used as database for smallholder farmers so that they easily be tracked be advised on good agricultural practices. The model is still under development but will be tested under different soil types and crops so that it can be widely used by users.

\section{References}

[1] Hodge, A. (2008) The Plastic Plant: Root Responses to Heterogeneous Supplies of Nutrients. New Phytologist, 162, 9-24.

[2] Buresh, R.J., Sanchez, P.A. and Calhoun, F., Eds. (1997) Replenishing Soil Fertility in Africa. Soil Society of America, Special Publication No. 51. Madison.

[3] Bauder, T.A. Waskom, R.M. and Andales, A. (2008) Nitrogen and Irrigation Management No. 0.514 Colorado State University Extension. 3/99. Revised 6/08. www.ext.colostate.edu

[4] Haefner, J.W. (1996) Modeling Biological Systems: Principles and Applications. Utah State University. Chapman and Hall. International Thomson Publishing. http://dx.doi.org/10.1007/978-1-4615-4119-6

[5] O’Leary, M., Rehm, G. and Schmitt, M. (2014) Understanding Nitrogen in Soils. http://www.extension.umn.edu/agriculture/nutrient-management/nitrogen/understanding-nitrogen-in-soils/

[6] Jury, W.A., Gardner, W.R. and Gardner, W.H. (1991) Soil Physics. 5th Edition, John Wiley and Sons, New York.

[7] Van Genuchten, M.Th., Leij, F.J. and Yates, S.R. (1991) The RETC Code for Quantifying the Hydraulic Functions of Unsaturated Soils. R. S. Kerr Environmental Research Laboratory, Ada.

[8] Vitousek, P.M., Hattenschwiler, S., Olander, L. and Allison, S. (2002) Nitrogen and Nature. Ambio., 31, 97-101.

[9] Nielsen, D.R., van Genuchten, M.Th. and Biggar, J.W. (1986) Water Flow and Solute Transport Processes in the Unsaturated Zone. Water Resources Research, 22, 89-108. http://dx.doi.org/10.1029/WR022i09Sp0089S

[10] Mulla, D.J. and Strock, J.S. (2008) Nitrogen Transport Processes in Soil. In: Schepers, J.S. and Raun, W.R., Eds., Nitrogen in Agricultural Systems, Agronomy Monograph 49. American Society of Agronomy, Crop Science Society of America, Soil Science Society of America, Madison.

[11] Berner, R.A. (1971) Principles of Chemical Sedimentology. McGraw-Hill, Inc., New York.

[12] Drever, J.I. (1982) The Geochemistry of Natural Waters. Prentice-Hall, Inc., Englewood Cliffs.

[13] Shackelford, C.D. and Daniel, D.E (1991) Laboratory Diffusion Testing for Waste Disposal-A Review. Contaminant Hydro., 7.

[14] Igbadun, H.E. (2006) Evaluation of Irrigation Scheduling Strategies for Improving Water Productivity: ComputerBased Simulation Model Approach. Ph.D. Dissertation, Sokoine University of Agriculture, Morogoro. 
Scientific Research Publishing (SCIRP) is one of the largest Open Access journal publishers. It is currently publishing more than 200 open access, online, peer-reviewed journals covering a wide range of academic disciplines. SCIRP serves the worldwide academic communities and contributes to the progress and application of science with its publication.

Other selected journals from SCIRP are listed as below. Submit your manuscript to us via either submit@scirp.org or Online Submission Portal.
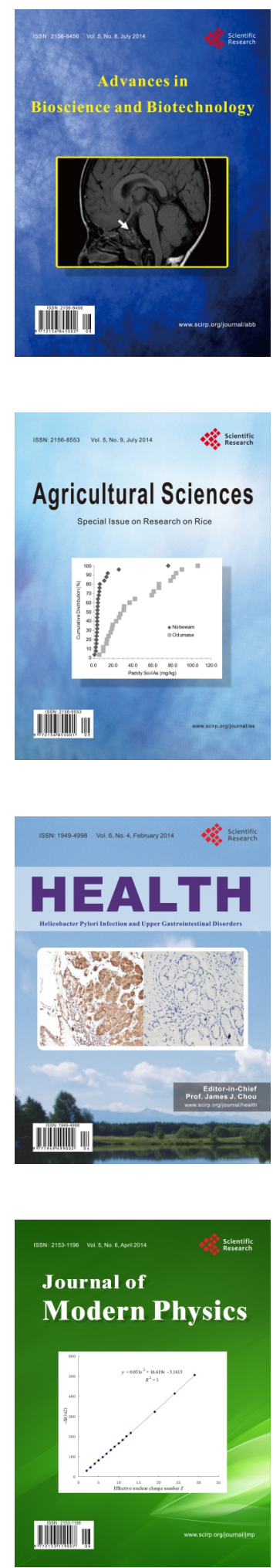
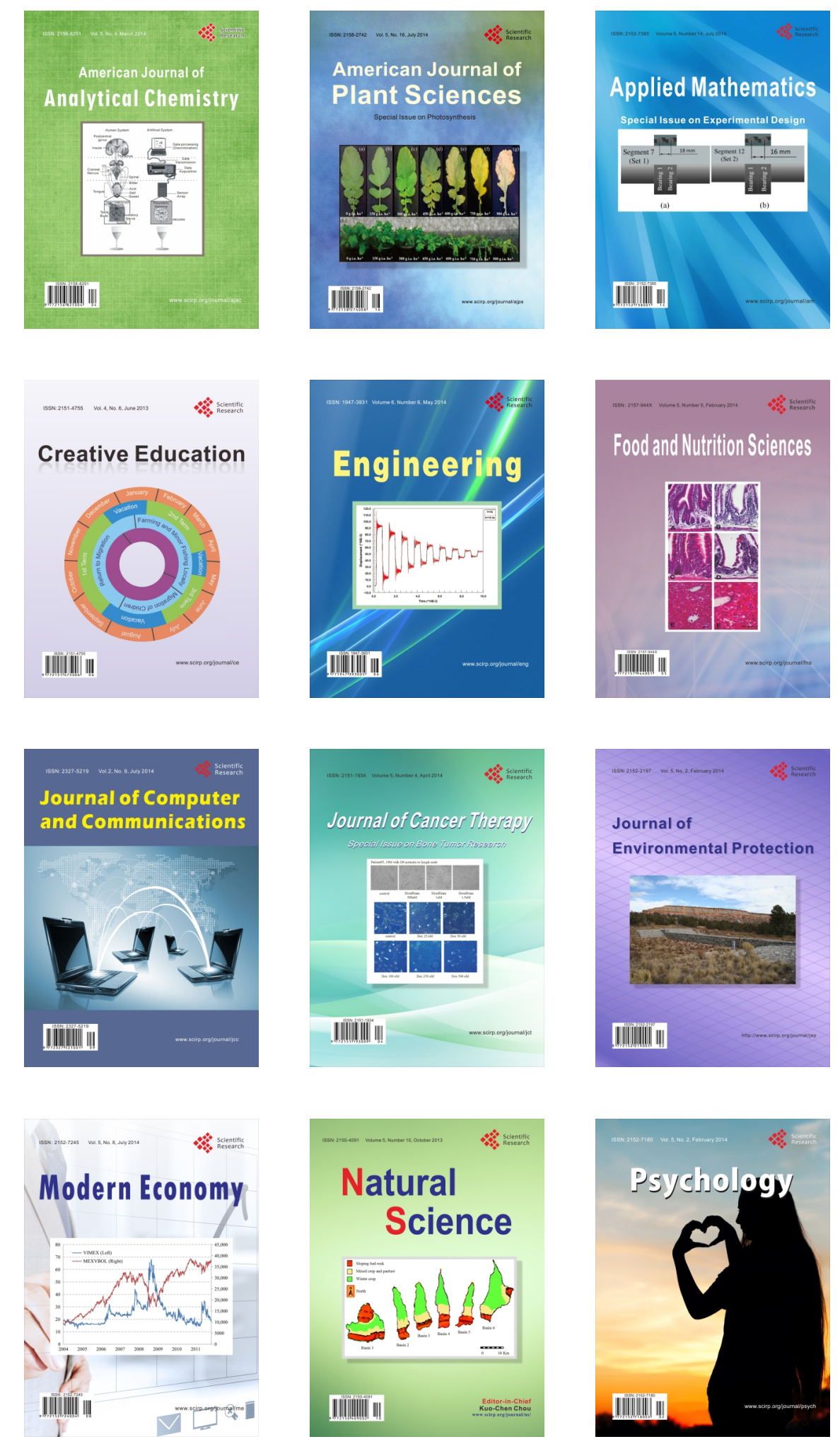